Article

\title{
Soft and Hard Piezoelectric Ceramics for Vibration Energy Harvesting
}

\author{
Xiaodong Yan, Mupeng Zheng *, Mankang Zhu and Yudong Hou \\ Key Laboratory of Advanced Functional Materials, Ministry of Education, Faculty of Materials and \\ Manufacturing, Beijing University of Technology, Beijing 100124, China; yxd0716@163.com (X.Y.); \\ zhumk@bjut.edu.cn (M.Z.); ydhou@bjut.edu.cn (Y.H.) \\ * Correspondence: mpzheng@bjut.edu.cn
}

Received: 3 September 2020; Accepted: 3 October 2020; Published: 7 October 2020

\begin{abstract}
The question as to which piezoelectric composition is favorable for energy harvesting has been addressed in the past few years. However, discussion on this topic continues. In this work, an answer is provided through a feasible method which can be used in selecting piezoelectric material. The energy harvesting behavior of hard (P4 and P8) and soft (P5 and P5H) lead zirconate titanate (PZT) ceramics was investigated. The results show that the maximum piezoelectric voltage coefficient $g_{33}$ and transduction coefficient $d_{33} \times g_{33}$ were obtained in P5 ceramic. Meanwhile, the power generation characteristics at low frequencies were compared by the vibration energy harvester with a cantilever beam structure. The results indicate that the energy harvester fabricated by the P5 ceramic with the maximum $d_{33} \times g_{33}$ values also demonstrated the best power generation characteristics. The results unambiguously demonstrate that the power density and energy conversion efficiency of the energy harvesting devices are dominated by the $d_{33} \times g_{33}$ value of the piezoelectric materials.
\end{abstract}

Keywords: PZT; perovskite; energy harvesting; cantilever beam; power generation

\section{Introduction}

With the development of the Internet of Things and artificial intelligence technology, current power sources such as batteries have limitations in microelectronics due to their large volume, limited lifetime, etc. [1]. Thus, there has been extensive interest in the concept of piezoelectric energy harvesting, which is a process of recycling ambient waste vibration energy and converting it into useable electricity [2]. This technology aims to eliminate the need for replacing chemical batteries or complex wiring in microsystems, moving us closer toward batteryless autonomous sensors systems and networks [3].

In order to achieve high electromechanical energy conversion efficiency in application, as the core component of the energy harvester, piezoelectric materials have been subjected to considerable challenges. Priya et al. [4] proposed that the key factor for the selection of a piezoelectric material for energy harvesting applications is the high energy density $u$, which can be calculated by the following formula:

$$
u=\frac{1}{2}(d \times g)\left(\frac{F}{A}\right)^{2}
$$

where $d$ is the piezoelectric charge constant, $g$ is the piezoelectric voltage constant, $F$ is the applied alternating force, and $A$ is the force area. According to Equation (1), for a given material with fixed $A$ and the same applied force, the piezoelectric materials with large transduction coefficient $(d \times g)$ will generate high energy density. Recently, many studies have been attempted to search for such piezoelectric materials [5-12]. However, there is still no direct experimental evidence to clarify the relationship between the $d \times g$ value of materials and the power generation characteristic of energy harvesters. 
$\mathrm{Pb}(\mathrm{Zr}, \mathrm{Ti}) \mathrm{O}_{3}(\mathrm{PZT})$, a classic ferroelectric system, possesses superior piezoelectric properties as well as temperature stability [13]. Further modifications using acceptor and donor dopants give us the wide range of piezoelectric compositions [14]. Acceptor dopants include lower valence additives, which play a hardening role in the ferroelectrics by pinning domain wall motion and thus reducing internal loss and enhancing coercive field, but at the expense of decreasing dielectric and piezoelectric properties, such compositions were defined as hard ferroelectrics [15]. In contrast, donor dopants, which include higher valence additives, generate lead vacancies and subsequent enhancement of domain wall mobility, resulting in the soft ferroelectrics with higher dielectric and piezoelectric properties.

The aim of this work is mainly to clarify whether a piezoelectric ceramic with high transduction coefficient $(d \times g)$ also has excellent power generation performances. Various piezoelectric composition (hard (P4, P8) and soft (P5, P5H) PZT) were considered for this purpose and it was found that the soft P5 ceramic not only possessed the highest $d \times g$ value, but also performed the best power generation performances.

\section{Experimental Procedure}

PZT samples (P4, P8, P5, and P5H) were obtained from BaoDing HongSheng Acoustics Electron Apparatus Co., Ltd. (Baoding, China) [16]. The specimens with dimensions $10 \mathrm{~mm} \times 10 \mathrm{~mm} \times 0.5 \mathrm{~mm}$ and an electrode on the main surfaces were adopted to assess the energy harvesting behavior. The dielectric properties $\left(\varepsilon_{\mathrm{r}}\right.$ and $\left.\tan \delta\right)$ were measured by employing a multifrequency LCR analyzer (Agilent E4980A, Santa Clara, CA, USA). The ferroelectric properties of the samples were studied by employing a ferroelectric tester (Premier II, Radiant Technologies Inc., Albuquerque, NM, USA) at $1 \mathrm{~Hz}$. The piezoelectric charge constant $d_{33}$ of these specimens was measured utilizing a piezoelectric $d_{33}$ meter (ZJ-6A, Institute of Acoustics, Academic Sinica, China) at $100 \mathrm{~Hz}$. The piezoelectric voltage constant $g_{33}$ and figure of merit in the off-resonance condition $\left(\mathrm{FOM}_{\text {off }}\right)$ can be calculated by using Equations (2) and (3) [4]:

$$
\begin{aligned}
g_{33} & =\frac{d_{33}}{\varepsilon_{0} \varepsilon_{\mathrm{r}}} \\
\mathrm{FOM}_{o f f} & =\frac{d_{33} \times g_{33}}{\tan \delta}
\end{aligned}
$$

For piezoelectric application, electromechanical coupling factors $\left(k_{\mathrm{p}}\right)$ can reflect the conversion ability between electrical and mechanical energy [17], which can be directly derived from resonance $\left(f_{\mathrm{r}}\right)$ and antiresonance frequencies $\left(f_{\mathrm{a}}\right)$, as shown below:

$$
k_{\mathrm{p}}=\sqrt{2.51 \times \frac{f_{\mathrm{a}}-f_{\mathrm{r}}}{f_{\mathrm{r}}}}
$$

In addition, the mechanical quality factor $\left(Q_{\mathrm{m}}\right)$ is also a major parameter for resonant applications and can reflect the degree of energy dissipation. The $Q_{\mathrm{m}}$ value can be calculated by

$$
Q_{\mathrm{m}}=\frac{f_{\mathrm{a}}^{2}}{2 \pi f_{\mathrm{r}} R C\left(f_{\mathrm{a}}^{2}-f_{\mathrm{r}}^{2}\right)}
$$

where $R$ is the impedance at $f_{\mathrm{r}}$ and $C$ is the capacitance under $1 \mathrm{kHz}$. Here, $k_{\mathrm{p}}$ and $Q_{\mathrm{m}}$ were obtained by a precision impedance analyzer (Agilent 4294A, Santa Clara, CA, USA).

To produce the cantilever-type piezoelectric energy harvester, the ceramics were attached to stainless steel substrates $(120 \mathrm{~mm} \times 12 \mathrm{~mm} \times 0.9 \mathrm{~mm})$ using epoxy (353ND; Epoxy Technology, Billerica, MA, USA). The detailed experimental method and the related instruments can be found in our previous works [11,18]. 


\section{Results and Discussion}

These commercial ceramics present a complete perovskite structure without any trace of impurities, as shown in Figure 1. To further study their crystal structure, $(200)_{p c}$ reflections of the samples were enlarged and are presented in Figure S1 (in Supplementary Material). As we can see, four patterns show the identifiable but incomplete splitting, implying that these compositions are all located at around the morphotropic phase boundary (MPB) $[19,20]$. By using the Gaussian method, the $(200)_{p c}$ patterns of the four ceramics were fitted based on a mixture of $\mathrm{R}$ and $\mathrm{T}$ phases [21]. The results indicate that the fraction of $\mathrm{T}$ phase for $\mathrm{P} 4, \mathrm{P} 8, \mathrm{P} 5$, and $\mathrm{P} 5 \mathrm{H}$ was $79.6 \%, 86.7 \%, 66.6 \%$ and $75.0 \%$, respectively. All of the PZT ceramics retained a high relative density of above $95 \%$ and a uniform microscopic appearance. The SEM micrographs and grain size distributions are displayed in Figure $2 \mathrm{a}-\mathrm{h}$, and average grain sizes of the P4, P8, P5, P5H ceramics are approximately 2.80, 2.14, 3.02, and $11.77 \mu \mathrm{m}$, respectively.

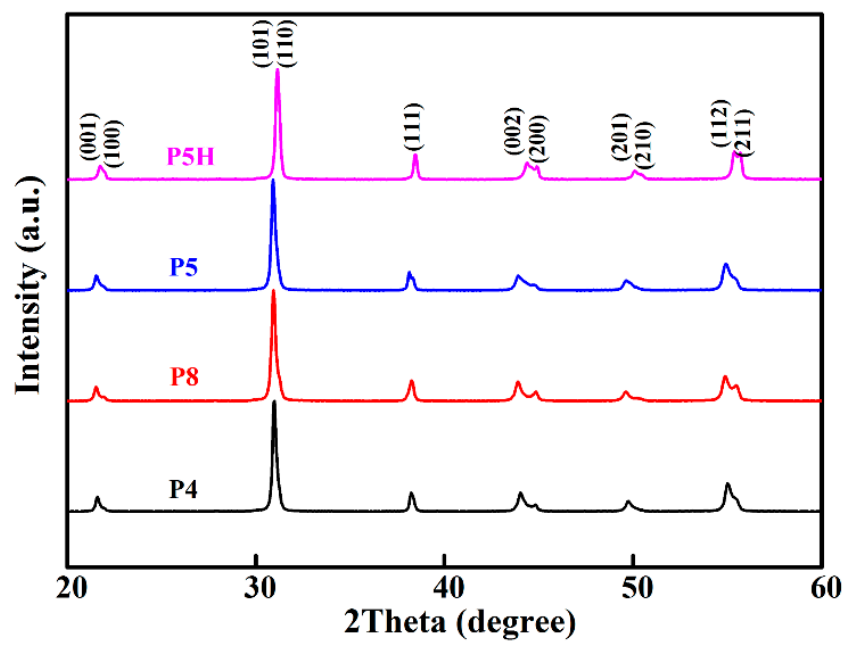

Figure 1. XRD patterns of the hard and soft $\mathrm{Pb}(\mathrm{Zr}, \mathrm{Ti}) \mathrm{O}_{3}(\mathrm{PZT})$ ceramics.

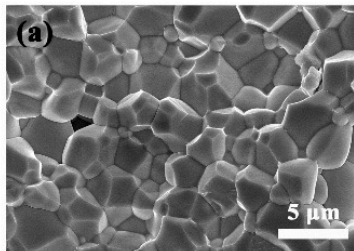

(e)

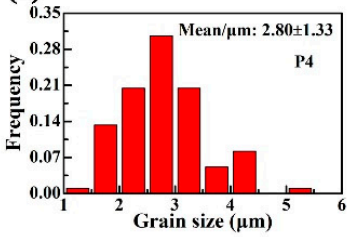

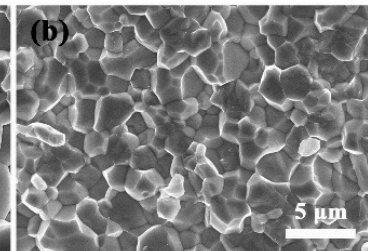

(f)

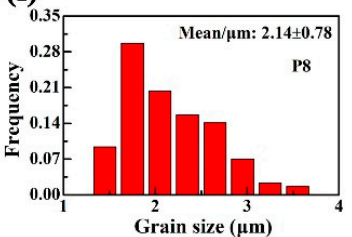

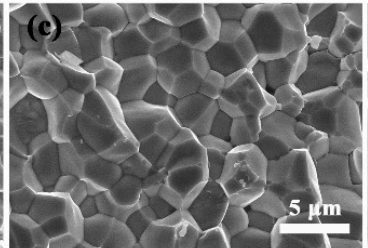

(g)

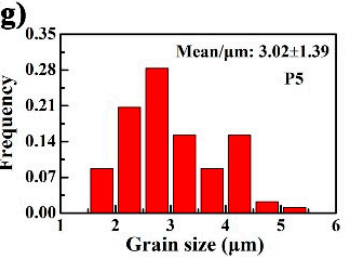

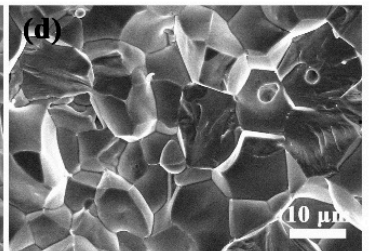

(h)

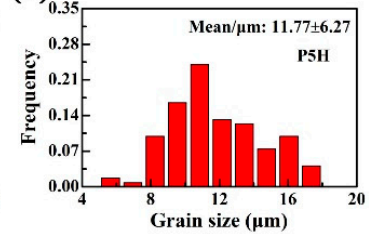

Figure 2. SEM micrographs and grain size distributions of the hard and soft PZT ceramics: (a), (e) P4; (b), (f) P8; (c), (g) P5; (d), (h) P5H.

Figure 3a-d show the polarization $(P)$-electric field $(E)$ hysteresis loops and corresponding current density $(J)-E$ curves of the commercial hard and soft PZT ceramics, respectively. Figure 3a gives the representative $P-E$ loop of $P 4$ ceramic, as we can see, the off-set in coercive field arises, and reflects the level of internal bias [15]. It is well known that the development of internal bias can effectively increase the coercive field and decrease the remanent polarization of hard piezoelectrics. The strong loop pinching is observed in the much harder P8 ceramic [Figure 3b], which may be due to the resorting force for domain walls and constrain their motion caused by oxygen vacancy-acceptor defect dipoles [22]. Soft $\mathrm{P} 5$ and $\mathrm{P} 5 \mathrm{H}$ ceramics result in the opposite effect of hard piezoelectrics, with the 
remanent polarization increasing, while the coercive field decreases, as shown in Figure 3c,d. It is noted that the flats in $J-E$ curves were due to the generated current responses exceeding the detection limit of the ferroelectric tester. These "hardening" and "softening" effects would also change the dielectric and piezoelectric activity shown in Figure 4a, which gives the typical electrical properties of hard and soft piezoelectric polycrystals [15].
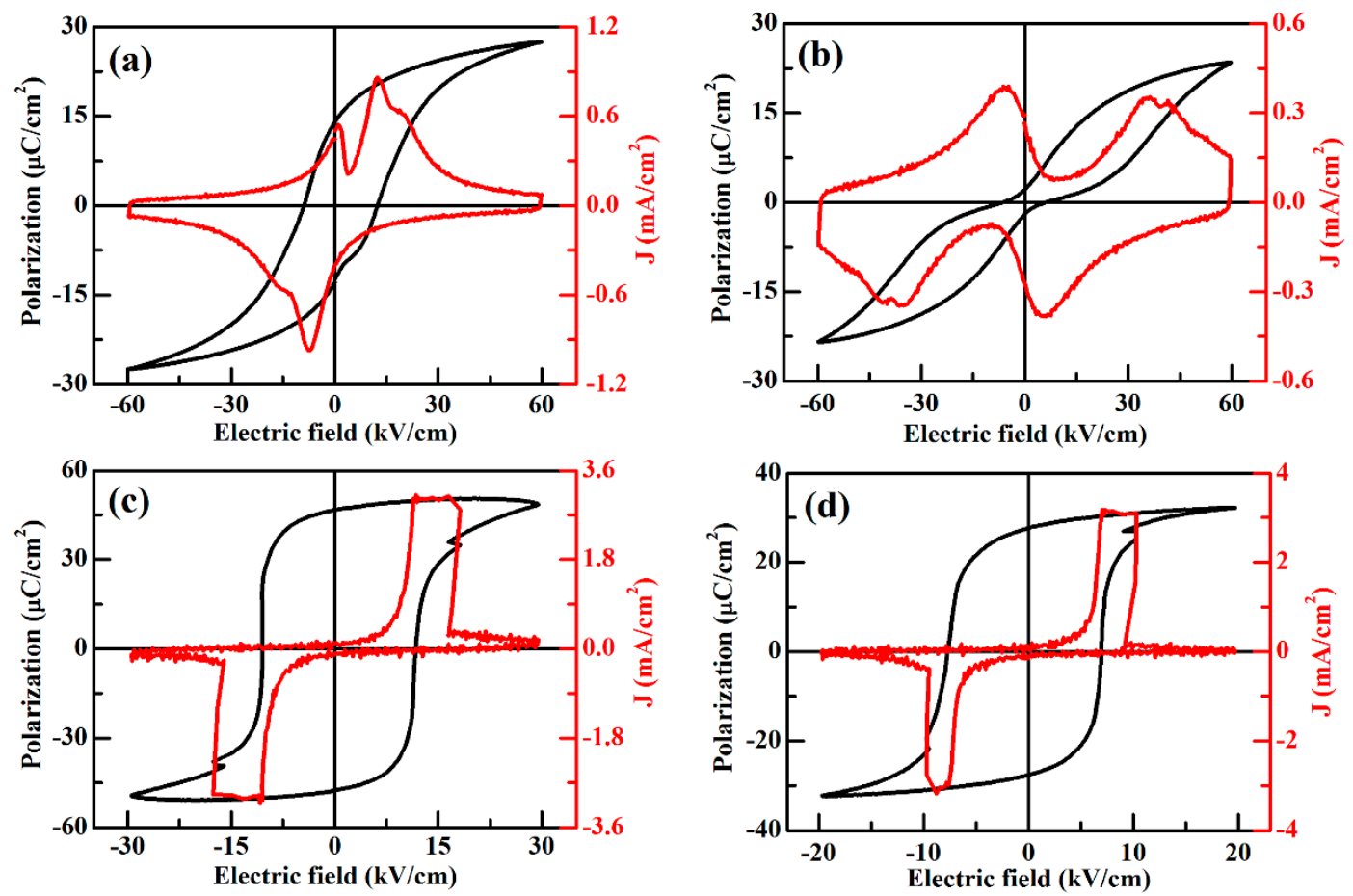

Figure 3. The polarization-electric field $(P-E)$ hysteresis loops and the current density-electric field $(J-E)$ curves measured $1 \mathrm{~Hz}$ for PZT ceramics: (a) P4, (b) P8, (c) P5, and (d) P5H.

In the process of converting vibration energy into electrical energy, it is difficult to evaluate the piezoelectric energy harvesting material by considering only a single property index [4]. According to previous reports, the piezoelectric voltage constant $\left(g_{33}\right)$, transduction coefficient $\left(d_{33} \times g_{33}\right)$, and figure of merit in the off-resonance condition $\left(\mathrm{FOM}_{\text {off }}\right)$ may be important factors to determine the electromechanical conversion performance of commercial PZT ceramics at low frequencies, as shown in Figure $4 \mathrm{~b}$. It is found that the maximum $g_{33}$ and $d_{33} \times g_{33}$ value of $36 \times 10^{-3}$ and $20,500 \times 10^{-15} \mathrm{~m}^{2} / \mathrm{N}$ were obtained in $\mathrm{P} 5$ ceramic, respectively, while the maximum $\mathrm{FOM}_{\text {off }}$ value of $32.4 \times 10^{-10} \mathrm{~m}^{2} / \mathrm{N}$ was obtained in P8 ceramic due to the low loss $(\tan \delta)$ of $0.18 \%$ in harder piezoelectric ceramic. Generally, the loss plays a critical role in affecting the electrical damping [4], which further influences the performance of the transducer.

Furthermore, the vibration energy harvesters based on these PZT commercial ceramics were fabricated, as shown in Figure 5. The cantilever was mounted on a shaker, and the top and bottom electrodes were connected to load resistance by lead lines [11]. The continuous vibration with the sine wave modes was applied and the generated voltage could be observed by an oscilloscope. Figure 6a gives the frequency-dependent voltage (open circuit) of the PZT energy harvesters at an acceleration of $1.0 \mathrm{~g}$. The resonance frequency for the energy harvester located at $92 \mathrm{~Hz}$, where the highest output voltage (open circuit) of $30.3 \mathrm{~V}$ (amplitude value) was achieved in an energy harvester fabricated by P5 ceramic. Figure $6 \mathrm{~b}$ depicts the output voltage (amplitude value), output current (amplitude value), and average output power as a function of external load. When increasing the load resistance, the output voltage across the load increased while the output current decreased gradually. The peak power values of all the PZT energy harvesters were obtained at a resistance of $200 \sim 1200 \mathrm{k} \Omega$, which depend on the internal impedance of piezoelectric materials [23]. 

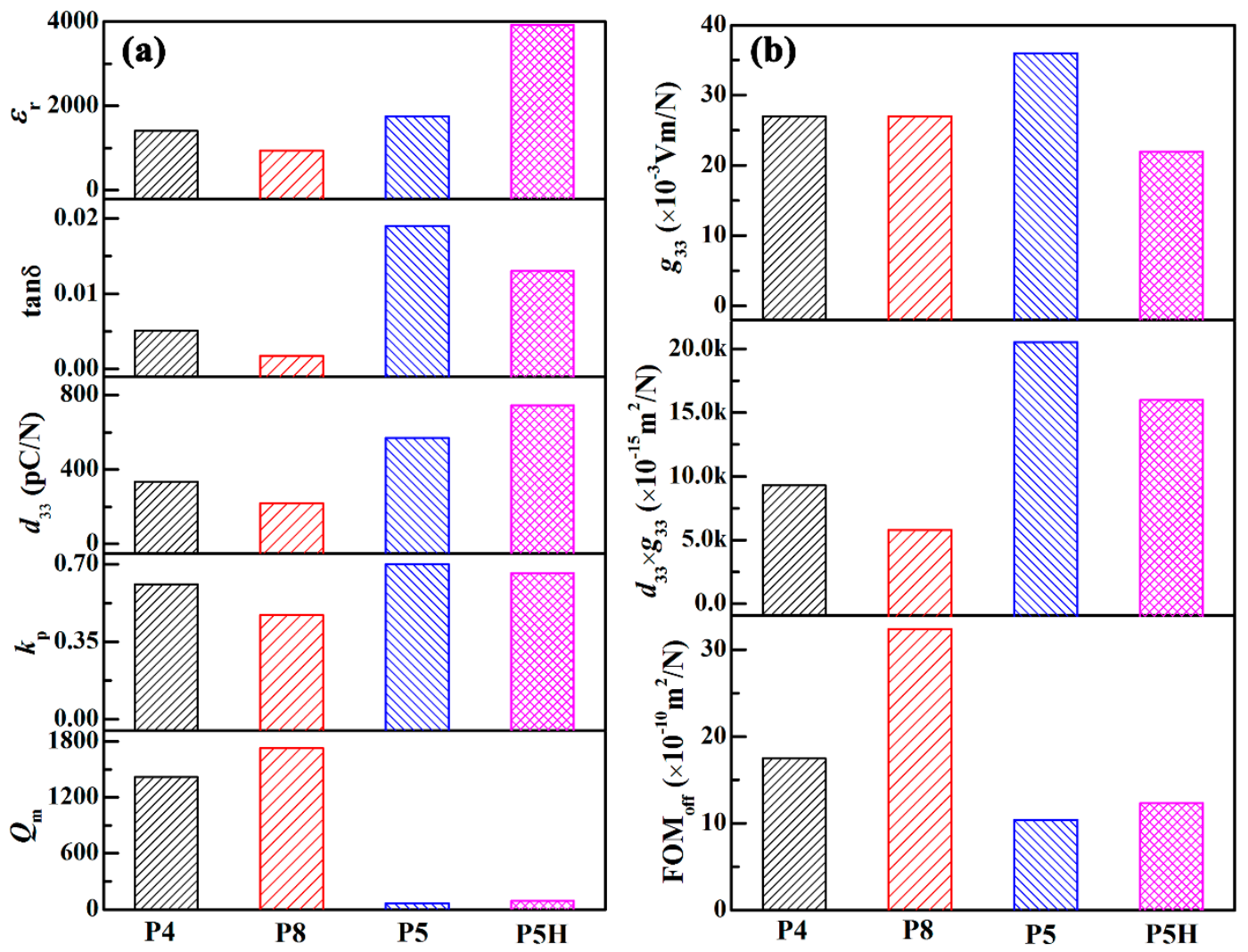

Figure 4. (a) Dielectric and piezoelectric characteristics; (b) energy harvesting performance of P4, P8, $\mathrm{P} 5$ and $\mathrm{P} 5 \mathrm{H}$ piezoelectric ceramics.

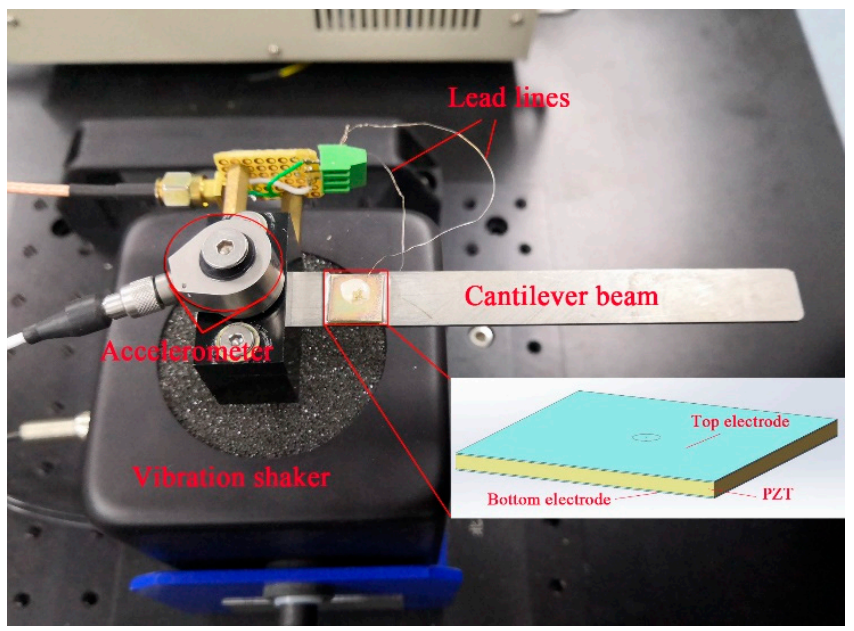

Figure 5. The experimental equipment of the piezoelectric energy harvester. 

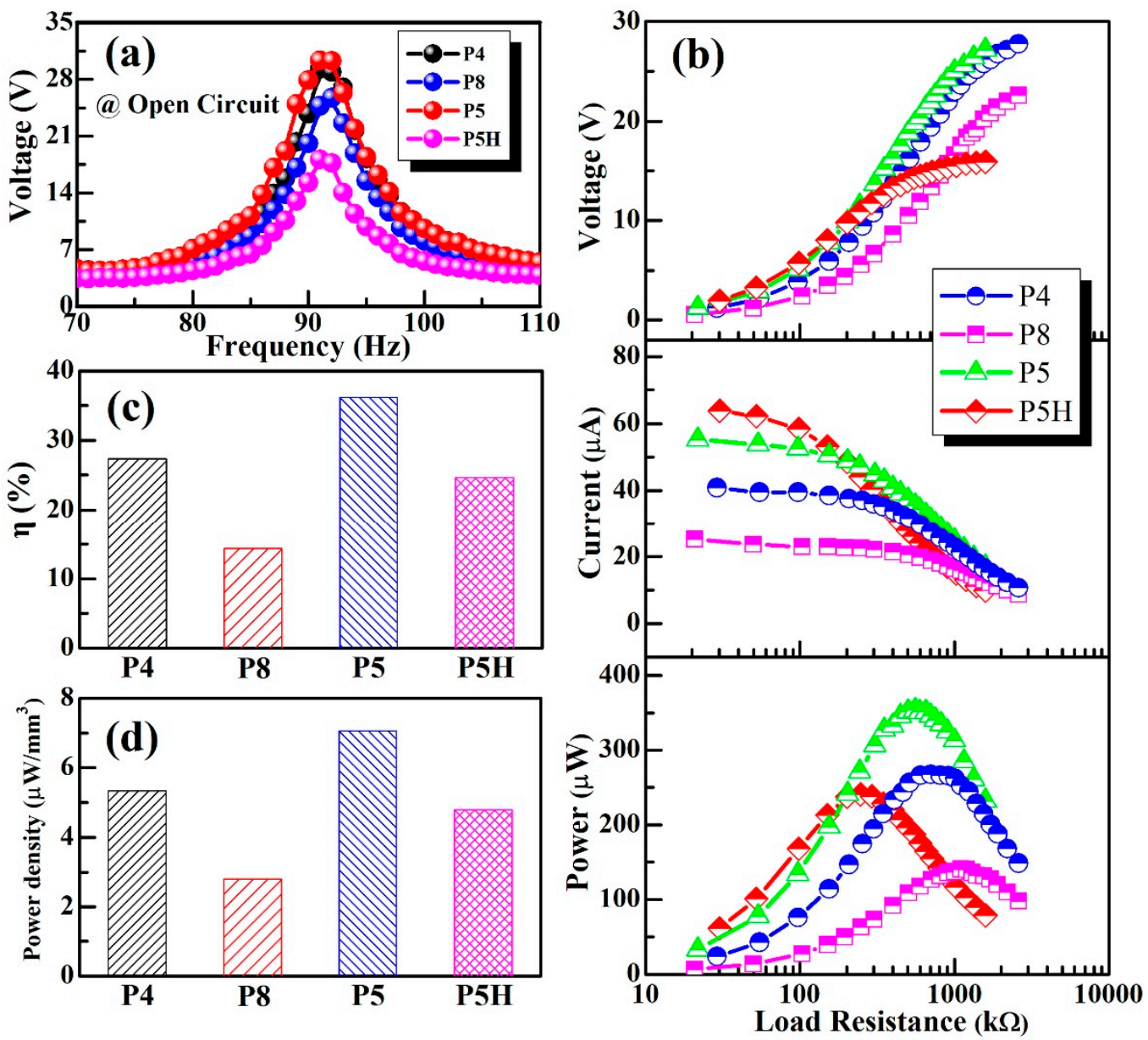

Figure 6. (a) The frequency dependence of voltage, (b) output voltage amplitude, output current amplitude, and average output power as a function of external load resistance, (c) energy conversion efficiency, and (d) power density for the energy harvesters fabricated with soft and hard PZT ceramics under $1.0 \mathrm{~g}$ vibration acceleration.

Energy conversion efficiency $(\eta)$ is an essential performance metric for energy harvesters and usually refers to the ratio of output electrical energy $\left(E_{\text {out }}\right)$ to input vibration energy $\left(E_{\text {in }}\right)$ [24]. However, the expressions of $E_{\text {out }}$ and $E_{\text {in }}$ vary in different papers [25-27]. Here, the input and output energy were defined by the following formula (6) [28,29]:

$$
\eta=\frac{E_{\mathrm{out}}}{E_{\mathrm{in}}}=\frac{P \cdot T}{\pi \cdot F_{0} \cdot z_{0}}
$$

where $E_{\text {in }}$ is the input mechanical energy to the entire cantilever beam, $E_{\text {out }}$ is the output electric energy to the external load, $z_{0}$ is the vibration amplitude of the cantilever beam from the equilibrium position, $T$ is a vibration cycle, $F_{0}$ is the amplitude of the harmonic excitation force, and $P$ is the average output power. Figure $6 \mathrm{c}$ plots the $\eta$ value of the PZT energy harvesters. It can be seen that the values of $\eta$ in PZT energy harvesters are all above $10 \%$. In particular, the $\eta$ value of P5 energy harvesters can reach as high as $36.2 \%$. Furthermore, Figure $6 \mathrm{~d}$ gives power density for the energy harvesters fabricated with soft and hard PZT ceramics, which shows the similar trend with the change in $\eta$ value [30]. The highest power density of $7.06 \mu \mathrm{W} / \mathrm{mm}^{3}$ was obtained in soft P5 piezoelectric ceramic.

Furthermore, we compared the power generation characteristics of energy harvesters fabricated by the hard and soft PZT ceramics at $92 \mathrm{~Hz}$, as depicted in Figure 7. It is found that the $d_{33} \times g_{33}$ values of these commercial ceramics showed a similar trend as the average output power, energy conversion efficiency, and power density change. The maximum values of output power, efficiency, and power 
density were all obtained in the energy harvester fabricated by the P5 sample, which has the largest $d_{33} \times g_{33}$ value.

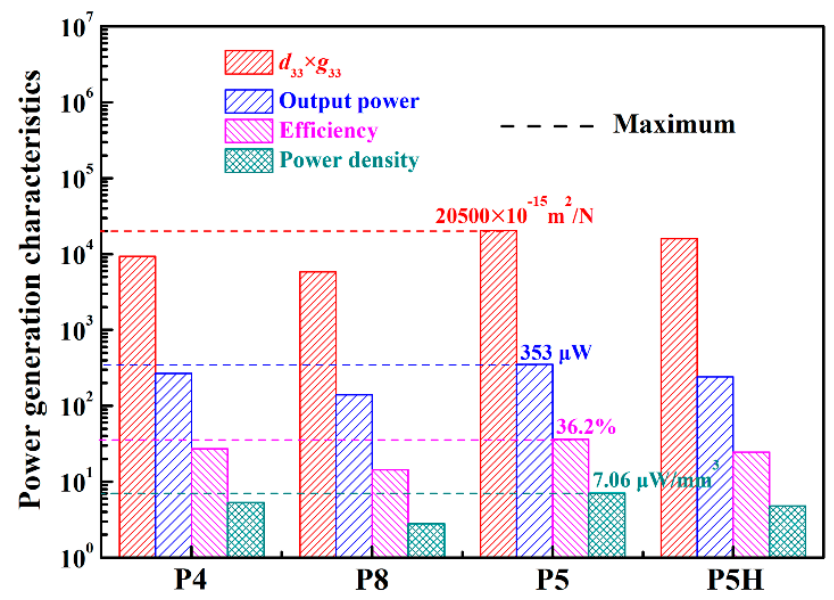

Figure 7. Comparison for the power generation characteristics of the hard and soft PZT ceramics.

\section{Conclusions}

This work provides a criterion for choosing piezoelectric materials that can be suitable for cantilever beam piezoelectric energy harvesters. The energy harvesting behavior of these commercial ceramics, including P4 (hard), P8 (harder), P5 (soft) and P5H (softer) have been investigated. The results unambiguously demonstrate important differences in the energy harvesting behavior and power generation performance among this family of materials and the energy harvesters fabricated by these commercial ceramics. The results further clearly show that at a low frequency region (e.g., $92 \mathrm{~Hz}$ ), the power generation performances of the energy harvesters are dominated by the $d_{33} \times g_{33}$ value of the piezoelectric materials.

Supplementary Materials: The following are available online at http://www.mdpi.com/2073-4352/10/10/907/s1, Figure S1: Comparison of (002)T, (200)R, and (200)T reflections (from left to right) for the hard and soft PZT ceramics: (a) P4, (b) P8, (c) P5, and (d) P5H.

Author Contributions: Data curation, X.Y.; Funding acquisition, M.Z. (Mupeng Zheng) and Y.H.; Investigation, M.Z. (Mankang Zhu); Writing—original draft, X.Y and M.Z. (Mupeng Zheng); Writing-review \& editing, M.Z. (Mankang Zhu) and Y.H. All authors have read and agreed to the published version of the manuscript.

Funding: This research was funded by National Natural Science Foundation of China (Grant No. 51677001, 51602012), Beijing Natural Science Foundation (Grant No. 2192009, 2202008), and Beijing Talents Project (Grant No. 2019A25).

Conflicts of Interest: The authors declare that they have no known competing financial interests or personal relationships that could have appeared to influence the work reported in this paper.

\section{References}

1. Shen, D.; Park, J.-H.; Ajitsaria, J.; Choe, S.-Y.; Wikle, H.C.; Kim, D.-J. The design, fabrication and evaluation of a MEMS PZT cantilever with an integrated Si proof mass for vibration energy harvesting. J. Micromech. Microeng. 2008, 18, 055017. [CrossRef]

2. Siang, J.; Lim, M.H.; Leong, M.S. Review of vibration-based energy harvesting technology: Mechanism and architectural approach. Int. J. Energy Res. 2018, 42, 1866-1893. [CrossRef]

3. Kim, S.-G.; Priya, S.; Kanno, I. Piezoelectric MEMS for energy harvesting. MRS Bull. 2012, 37, $1039-1050$. [CrossRef]

4. Priya, S. Criterion for material selection in design of bulk piezoelectric energy harvesters. IEEE T. Ultrason. Ferr. 2010, 57, 2610-2612. [CrossRef]

5. Islam, R.A.; Priya, S. Realization of high-energy density polycrystalline piezoelectric ceramics. Appl. Phys. Lett. 2006, 88, 032903. [CrossRef] 
6. Seo, I.-T.; Cha, Y.-J.; Kang, I.-Y.; Choi, J.-H.; Nahm, S.; Seung, T.-H.; Paik, J.-H.; Priya, S. High Energy Density Piezoelectric Ceramics for Energy Harvesting Devices. J. Am. Ceram. Soc. 2011, 94, 3629-3631. [CrossRef]

7. Yan, Y.; Cho, K.-H.; Maurya, D.; Kumar, A.; Kalinin, S.; Khachaturyan, A.; Priya, S. Giant energy density in (001)-textured $\mathrm{Pb}\left(\mathrm{Mg}_{1 / 3} \mathrm{Nb}_{2 / 3}\right) \mathrm{O}_{3}-\mathrm{PbZrO}_{3}-\mathrm{PbTiO}_{3}$ piezoelectric ceramics. Appl. Phys. Lett. 2013, 102, 042903. [CrossRef]

8. Yuan, D.; Yang, Y.; Hu, Q.; Wang, Y.; Lupascu, D.C. Structures and Properties of $\mathrm{Pb}\left(\mathrm{Zr}_{0.5} \mathrm{Ti}_{0.5}\right) \mathrm{O}_{3}-\mathrm{Pb}\left(\mathrm{Zn}_{1 / 3} \mathrm{Nb}_{2 / 3}\right) \mathrm{O}_{3}-\mathrm{Pb}\left(\mathrm{Ni}_{1 / 3} \mathrm{Nb}_{2 / 3}\right) \mathrm{O}_{3}$ Ceramics for Energy Harvesting Devices. J. Am. Ceram. Soc. 2014, 97, 3999-4004. [CrossRef]

9. Hur, J.; Kim, J.-H.; Lee, T.-G.; Seo, I.-T.; Kim, D.-H.; Nahm, S.; Kang, C.-Y. Structural and Piezoelectric Properties of $(1-x) \mathrm{Pb}\left(\mathrm{Zr}_{1-\mathrm{y}} \mathrm{Ti}_{\mathrm{y}}\right) \mathrm{O}_{3}-x \mathrm{~Pb}\left(\mathrm{Zn}_{0.4} \mathrm{Ni}_{0.6}\right)_{1 / 3} \mathrm{Nb}_{2 / 3} \mathrm{O}_{3}$ Ceramics Near Triple Point. J. Am. Ceram. Soc. 2015, 98, 2887-2893. [CrossRef]

10. Zheng, M.-P.; Hou, Y.-D.; Ge, H.-Y.; Zhu, M.-K.; Yan, H. Effect of NiO additive on microstructure, mechanical behavior and electrical properties of 0.2PZN-0.8PZT ceramics. J. Eur. Ceram. Soc. 2013, 33, 1447-1456. [CrossRef]

11. Yan, X.D.; Zheng, M.P.; Hou, Y.D.; Zhu, M.K. Composition-driven phase boundary and its energy harvesting performance of BCZT lead-free piezoelectric ceramic. J. Eur. Ceram. Soc. 2017, 37, 2583-2589. [CrossRef]

12. Zheng, M.; Hou, Y.; Yan, X.; Zhu, M. The structural origin of enhanced energy harvesting performance in piezoelectric perovskite. J. Eur. Ceram. Soc. 2018, 38, 585-591. [CrossRef]

13. Haertling, G.H. Ferroelectric ceramics: History and technology. J. Am. Ceram. Soc. 1999, 82, 797-818. [CrossRef]

14. Shrout, T.R.; Zhang, S.J. Lead-free piezoelectric ceramics: Alternatives for PZT? J. Electroceram. 2007, 19, 113-126. [CrossRef]

15. Zhang, S.; Xia, R.; Lebrun, L.; Anderson, D.; Shrout, T.R. Piezoelectric materials for high power, high temperature applications. Mater. Lett. 2005, 59, 3471-3475. [CrossRef]

16. Li, F.; Xu, Z.; Wei, X.; Yao, X. Temperature- and dc bias field- dependent piezoelectric effect of soft and hard lead zirconate titanate ceramics. J. Electroceram. 2010, 24, 294-299. [CrossRef]

17. Zheng, T.; Wu, J.; Xiao, D.; Zhu, J. Recent development in lead-free perovskite piezoelectric bulk materials. Prog. Mater. Sci. 2018, 98, 552-624. [CrossRef]

18. Yan, X.D.; Zheng, M.P.; Gao, X.; Zhu, M.K.; Hou, Y.D. Giant current performance in lead-free piezoelectrics stem from local structural heterogeneity. Acta Mater. 2020, 187, 29-40. [CrossRef]

19. Wang, D.; Cao, M.; Zhang, S.; Jones, J.L. Investigation of Ternary System $\mathrm{PbHfO}_{3}-\mathrm{PbTiO}_{3}-\mathrm{Pb}\left(\mathrm{Mg}_{1 / 3} \mathrm{Nb}_{2 / 3}\right) \mathrm{O}_{3}$ with Morphotropic Phase Boundary Compositions. J. Am. Ceram. Soc. 2012, 95, 3220-3228. [CrossRef]

20. Tang, H.; Zhang, M.F.; Zhang, S.J.; Feng, Y.J.; Li, F.; Shrout, T.R. Investigation of dielectric and piezoelectric properties in $\mathrm{Pb}\left(\mathrm{Ni}_{1 / 3} \mathrm{Nb}_{2 / 3}\right) \mathrm{O}_{3}-\mathrm{PbHfO}_{3}-\mathrm{PbTiO}_{3}$ ternary system. J. Eur. Ceram. Soc. 2013, 33, 2491-2497. [CrossRef]

21. Zheng, M.P.; Hou, Y.D.; Xie, F.Y.; Chen, J.; Zhu, M.K.; Yan, H. Effect of valence state and incorporation site of cobalt dopants on the microstructure and electrical properties of 0.2PZN-0.8PZT ceramics. Acta Mater. 2013, 61, 1489-1498. [CrossRef]

22. Jin, L.; He, Z.; Damjanovic, D. Nanodomains in $\mathrm{Fe}^{3+}$-doped lead zirconate titanate ceramics at the morphotropic phase boundary do not correlate with high properties. Appl. Phys. Lett. 2009, 95, 012905.

23. Kim, H.W.; Batra, A.; Priya, S.; Uchino, K.; Markley, D.; Newnham, R.E.; Hofmann, H.F. Energy Harvesting Using a Piezoelectric “Cymbal” Transducer in Dynamic Environment. Jpn. J. Appl. Phys. 2004, 43, 6178-6183. [CrossRef]

24. Yang, Z.; Zu, J. Comparison of PZN-PT, PMN-PT single crystals and PZT ceramic for vibration energy harvesting. Energy Convers. Manage. 2016, 122, 321-329. [CrossRef]

25. Richards, C.D.; Anderson, M.J.; Bahr, D.F.; Richards, R.F. Efficiency of energy conversion for devices containing a piezoelectric component. J. Micromech. Microeng. 2004, 14, 717-721. [CrossRef]

26. Kim, M.; Dugundji, J.; Wardle, B.L. Efficiency of piezoelectric mechanical vibration energy harvesting. Smart Mater. Struct. 2015, 24, 055006. [CrossRef]

27. Crossley, S.; Kar-Narayan, S. Energy harvesting performance of piezoelectric ceramic and polymer nanowires. Nanotechnology 2015, 26, 344001. [CrossRef]

28. Shu, Y.C.; Lien, I.C. Efficiency of energy conversion for a piezoelectric power harvesting system. J. Micromech. Microeng. 2006, 16, 2429-2438. [CrossRef] 
29. Kubba, A.E.; Jiang, K. Efficiency enhancement of a cantilever-based vibration energy harvester. Sensors 2013, 14, 188-211. [CrossRef]

30. Yan, X.; Zheng, M.; Hou, Y.; Zhu, M.; Yan, H. High energy conversion efficiency in Mn-modified $\mathrm{Ba}_{0.9} \mathrm{Ca}_{0.1} \mathrm{Ti}_{0.93} \mathrm{Zr}_{0.07} \mathrm{O}_{3}$ lead-free energy harvester. J. Am. Ceram. Soc. 2018, 101, 2330-2338. [CrossRef] 